\title{
Drug-Drug Interaction Study
}

National Cancer Institute

\section{Source}

National Cancer Institute. Drug-Drug Interaction Study. NCI Thesaurus. Code C158286.

A type of study designed to evaluate the interaction between drugs, where the use of one may affect the disposition, efficacy, or safety of the other. 